\title{
ATRIAL SEPTAL DEFECT
}

BY

\section{LEWIS DEXTER*}

From the Medical Clinic, Peter Bent Brigham Hospital, and the Department of Medicine, Harvard Medical School, Boston, Massachusetts, U.S.A.

Received September 26, 1955

Atrial septal defect is one of the common types of congenital heart disease. Although recognized for centuries and receiving increasing attention since 1900, it was the detailed description by Bedford, Papp, and Parkinson in 1941, of the physical, electrocardiographic, radiological, and diagnostic features, the complications, and the clinical course, that brought the salient characteristics of this disorder to the attention of the medical profession. More recently, with the advent of new techniques of investigation, many publications have described the pathological physiology of the disease (Howarth et al., 1947; Barber et al., 1950; Lequime et al., 1950; Soulié et al., 1950; Puddu, 1952; Limón Lasón et al., 1953; Heim de Balzac et al., 1954). Finally, the introduction of surgical correction has given impetus to further inquiries into its many facets.

As Bedford, Papp, and Parkinson pointed out, there are a number of complications that occur and lead to varying degrees of incapacity-complications that may well have an important bearing on the risk of surgical intervention. It seems timely, therefore, to inquire further into the nature of this disorder and some of its complications-(1) hypoxæmia giving rise to cyanosis, (2) pulmonary vascular disease, (3) right ventricular failure, (4) left ventricular failure, and (5) mitral stenosis or Lutembacher's syndrome.

\section{MATERIAL}

Sixty patients have been studied by cardiac catheterization, as described elsewhere (Dexter et al., 1947). Seven of these patients were studied twice. There were 42 females and 18 males, ranging in age from 3 to 57 years.

Calculations of blood flow in patients with atrial septal defect are fraught with error. The narrow arteriovenous oxygen difference between pulmonary vein and artery associated with large pulmonary blood flows seriously interferes with the accuracy of the calculation by the Fick method. One may, in fact, be confronted with the distressing circumstances of having an arteriovenous oxygen difference so narrow as to be undetected by Van Slyke oxygen analysis, thus resulting in the calculation of an infinite pulmonary blood flow. There is no adequate site for obtaining mixed venous blood for the calculation of left ventricular cardiac output. We have used the superior vena cava. Errors involved in the calculation of ventricular outputs and shunts have been described in some detail (Dexter et al., 1947). These errors, however, do not detract from the usefulness of such measurements because they reflect large, medium, or normal right ventricular outputs; large, medium, or small left-to-right shunts; left ventricular outputs that at least are not raised and are in all probability subnormal; and right-to-left shunts that are small. The associated calculations of work and resistances necessarily suffer from the lack of precision of flow measurements, but it is believed that they are of similar value.

\footnotetext{
* This paper is based on the St. Cyres Lecture of the National Heart Hospital delivered in London on June 17, 1955. This work was supported in part by grants from the Life Insurance Medical Research Fund and the National Heart Institute, United States Public Health Service (grant H-450). 


\section{Pathological Physiology of Atrial Septal Defect}

Fig. 1 summarizes the salient findings in our patients, and Fig. 2 is a schema of the circulation in atrial septal defect. The atrial defect may vary in size from that of a small patent foramen ovale to complete absence of the septum. When the septal defect is small, the pressure in the left atrium is greater than in the right, and it is this pressure difference that has usually been considered to be responsible for the left-to-right shunt (Brannon et al., 1945; Cournand et al., 1947; Handelsman et al., 1948; Little et al., 1949; Wood, 1950; Martin and Essex, 1951 ; Calazel et al., 1951; and
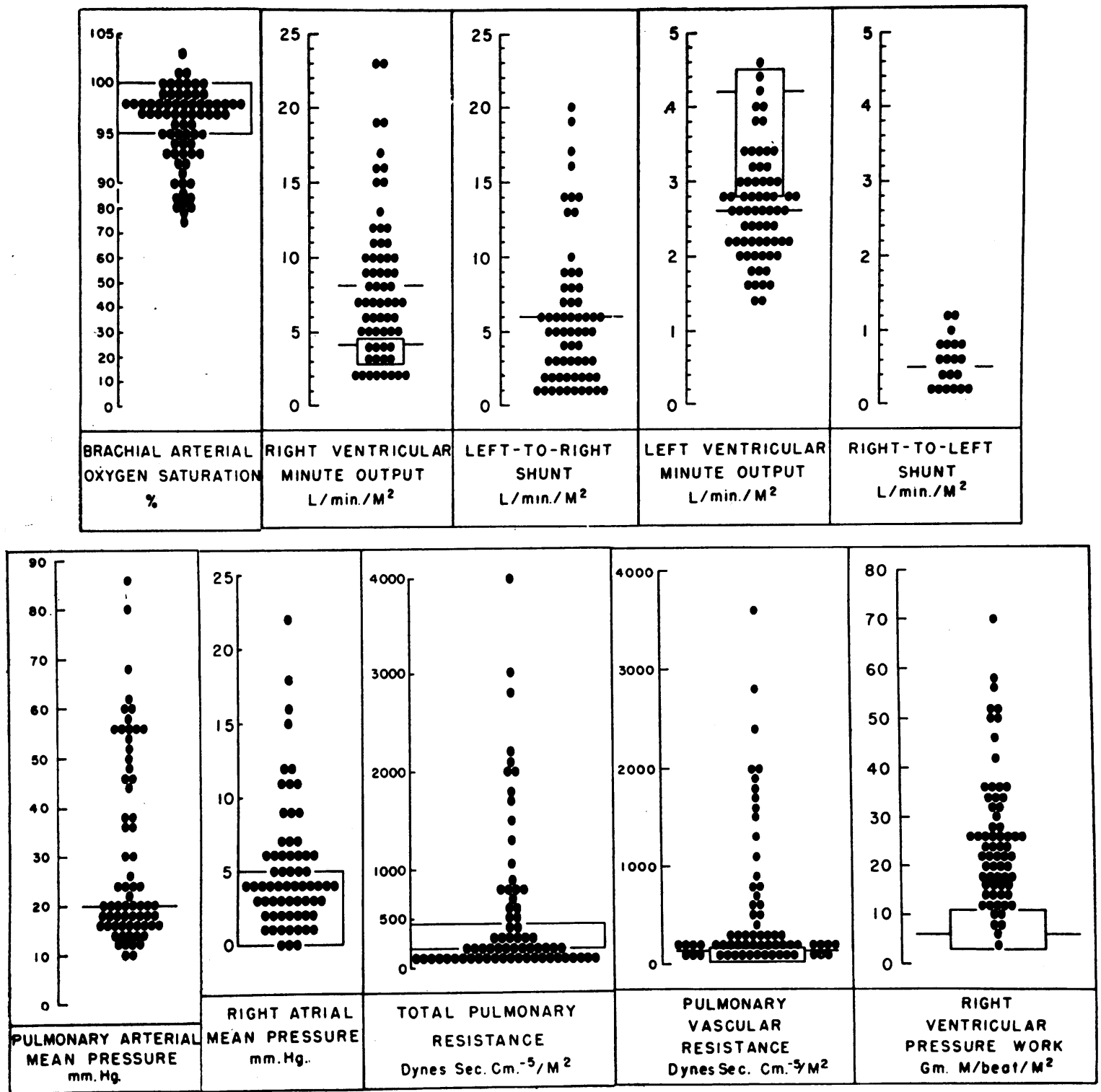

FIG. 1.-Circulatory findings in atrial septal defect. Summary of the salient features in 67 studies of 60 patients. The open boxes in each diagram represent the normal variations obtained under the same conditions of rest in this laboratory. 
Cosby et al., 1952). When the septal defect is large, however, there is a free communication between both atria and their respective venous systems and, during diastole, their respective ventricles, both in experimental animals (Dow and Maloney, 1950) and in man. Using highly sensitive manometers capable of recording pressure differences of less than $0.5 \mathrm{~mm}$. $\mathrm{Hg}$ accurately, no difference has been detected between left and right atrial pressures at the end of diastole in eight of our
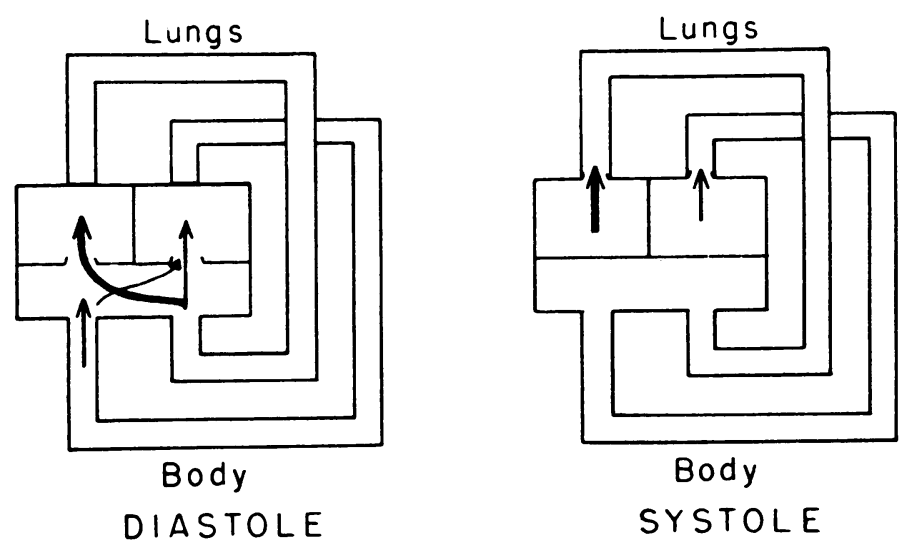

FIG. 2.-Schematic representation of the circulation in cases with a large atrial septal defect. Left. During diastole, pressures are almost identical in both ventricles, the common atrium, and both venous systems. The right ventricle, being more distensible than the left, fills to a much greater degree than the left at the same filling or diastolic pressure. As indicated by the heavy arrow, this results in a large left-to-right shunt. In some cases there is a bi-directional shunt and in others a right-to-left shunt alone (see text for discussion). The right-to-left shunt is always small. Right. During systole, each ventricle discharges the blood received during diastole into its respective circuit. The left-to-right shunt at the atrial level, taking place during systole, can get no farther than the right atrium, since the mitral and tricuspid valves are closed.

cases, in two it was less than $1.0 \mathrm{~mm} . \mathrm{Hg}$, in one it was $2 \mathrm{~mm}$. $\mathrm{Hg}$, and in two it was $3 \mathrm{~mm}$. $\mathrm{Hg}$. The average difference between left and right atrial end-diastolic pressure was $0.7 \mathrm{~mm}$. $\mathrm{Hg}$. In the instances where pressures were satisfactorily measured, no difference of pressure was found between left ventricular and left atrial end-diastolic pressure in 11 cases or between right ventricular and right atrial end-diastolic pressure in 31 cases.

In patients with the largest left-to-right shunts, mean and end-diastolic pressures in the two atria have uniformly been found to be identical, confirming the suggestion of Barger et al. (1948) and of Hull (1949) that the main cause of the left-to-right shunt in patients with atrial septal defect is the greater distensibility of the right ventricle than the left when confronted with equal filling pressures (Dow and Dexter, 1950).

When the atrial septum is intact, pressure in the left atrium is normally $5 \mathrm{~mm} . \mathrm{Hg}$ or more higher than in the right. In the presence of a small atrial defect, this pressure gradient is maintained to a variable degree, depending on the size of the defect. With large defects of over two sq. $\mathrm{cm}$., the pressure difference between the two atria is practically abolished.

It is concluded that when septal defects are large, pressures in both atria and both ventricles, and both venous systems become equal at the end of diastole; when the defects are so small that a free communication does not exist, a pressure difference exists between the two atria during diastole approaching the pressure difference that normally exists between the two sides of the heart in diastole.

The arrows in the schema represent the characteristic shunts in atrial septal defect. The main 
shunt is from left to right and at times is enormous. This left-to-right shunt takes place mainly in diastole, when both venous systems, both atria, and both ventricles are in free communication. During systole, mitral and tricuspid valves close and both ventricles eject their contents into their respective arterial systems. The right ventricular output, which may be huge, passes through the low resistance area of the lung and on into the common atrium. A variable proportion of this large flow then passes around and around this circuit, never getting out to the tissues of the body and representing only wasted energy expenditure on the part of the right ventricle.

Some patients have a small right-to-left shunt, as indicated by the smaller arrow in Fig. 2. Its nature and cause will be discussed more fully later. The left ventricular output, as calculated, is less than normal or at least is not raised and is remarkably constant from patient to patient.

Pressures in the right ventricle and pulmonary artery may be normal or variably raised. Modest rises of pressure may be explained solely by increased flow when this exceeds 10 litres/minute/sq.m. (Dexter et al., 1950), and in these cases the calculated pulmonary vascular resistance is normal or low. In other cases the raised pressure may be all out of proportion to the increased flow. This is due to the presence of pulmonary vascular disease, which is one of the most serious complications of atrial septal defect. It obstructs the flow of blood through the lung and is best expressed physiologically by calculation of the pulmonary vascular resistance

$$
\text { PVR }=\frac{\text { PAm }- \text { LAm }}{\mathrm{F}} \times 1332
$$

where PVR $=$ the pulmonary vascular resistance, in dynes seconds $\mathrm{cm} \cdot \cdot^{-5} / \mathrm{sq} . \mathrm{m}$.

PAm = pulmonary arterial mean pressure, in $\mathrm{mm}$. $\mathrm{Hg}$.

$\mathrm{LAm}=$ left atrial mean pressure, in $\mathrm{mm}$. Hg (or pulmonary " capillary" mean or, in the presence of a large atrial septal defect, right atrial mean pressure).

$\mathrm{F}=$ pulmonary blood flow, in $\mathrm{ml} . /$ second/sq.m. body surface.

$1332=$ a conversion factor.

\section{Cyanosis (ARTERIAL OXYGen UnSATURATION)}

Cyanose tardive was first described by Bard and Curtillet (1889) and is a well-recognized complication of atrial septal defect. Of our 60 patients, 11 were clinically cyanotic and an additional 11 had decreased arterial oxygen saturation in a range in which cyanosis could not be detected clinically (Fig. 3). Studies by other investigators have indicated a far higher frequency of arterial

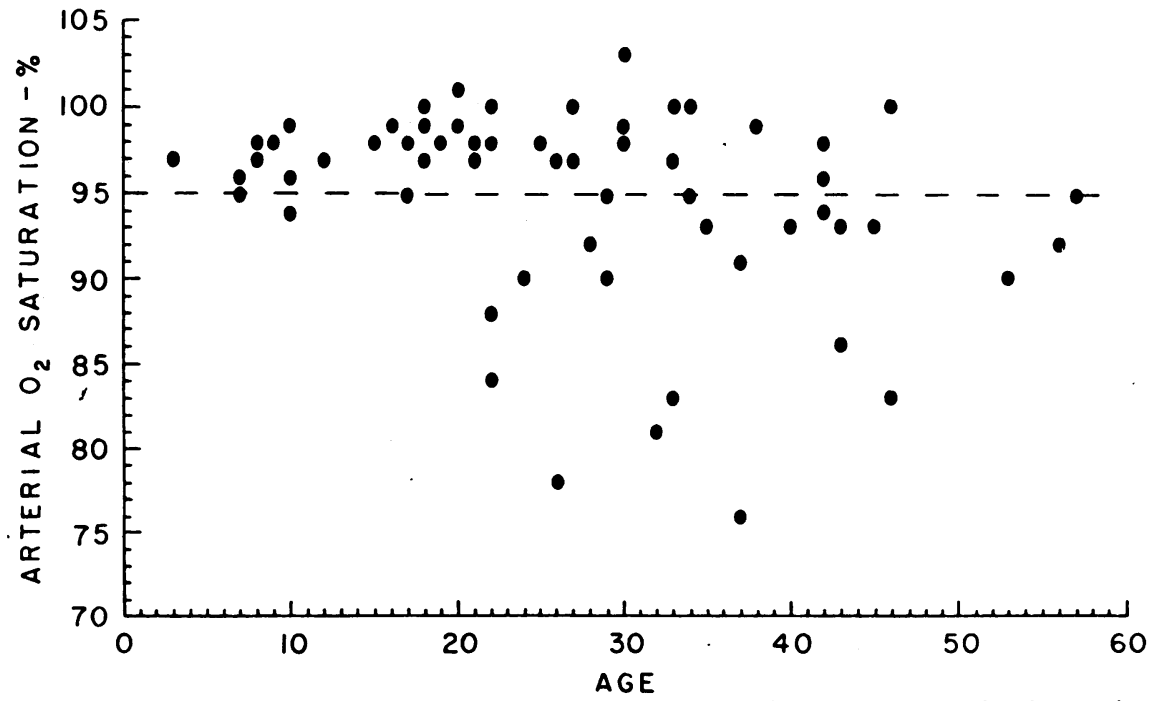

FIG. 3.-Relationship of arterial oxygen unsaturation with age. Note its increasing incidence with age and its rarity before the age of 20. Also observe that many patients in the older age group have a normal arterial oxygen saturation. 
oxygen unsaturation, which we are inclined to attribute either to the high altitude at which the studies were undertaken or to the use of sedatives, which we have not used in this study for experience has indicated that they lead to inconstant and varying degrees of arterial oxygen unsaturation. Fig. 3 shows the relation of arterial oxygen saturation to age; two points are at once apparent. There are increasing numbers of patients with arterial oxygen unsaturation with the passing years - the well-known cyanose tardive of atrial septal defect. On the other hand, some patients do not develop it even into the fifth and sixth decades. We have not observed arterial unsaturation in the younger age group in uncomplicated atrial septal defect of the secundum type except in the one case in Fig. 3-a patient aged 10, with an arterial oxygen saturation of 94 per cent. Cyanosis from birth has been described (Selzer and Lewis, 1949), but is rare.

The possible causes of cyanosis are as follows.

(A) Defective diffusion of oxygen across the alveolar-capillary membrane.

(B) Incomplete oxygenation of blood, due to the large pulmonary blood flow.

(C) Mixing of both venous bloods in the common atrium.

(D) Reversal of shunt.

(A) The pulmonary venous oxygen saturation has been uniformly normal, or practically so, in patients with oxygen unsaturation of the arterial blood and with varying degrees of pulmonary vascular resistance (see Table I). This confirms similar findings of Limón Lasón and Alvarez

TABLE I

Pulmonary Venous Oxygen Saturation in Patients with Brachial Arterial Oxygen Unsaturation at Various LeVels of Pulmonary Vascular Resistance -

\begin{tabular}{c|c|c|c}
\hline \multirow{2}{*}{ Patient } & \multicolumn{2}{|c|}{ Oxygen saturation (percentage) } & $\begin{array}{c}\text { Pulmonary } \\
\text { vascular resistance } \\
\text { (dynes sec. cm. }{ }^{-5} / \mathrm{m}^{2} \text { ) }\end{array}$ \\
\cline { 2 - 3 } & $\begin{array}{c}\text { Pulmonary } \\
\text { vein }\end{array}$ & $\begin{array}{c}\text { Brachial } \\
\text { artery }\end{array}$ & \\
\hline J.D. & 99 & 92 & 79 \\
S.W. & 95 & 95 & 132 \\
C.K. & 100 & 93 & 461 \\
M.M. & 94 & 93 & 513 \\
E.S. & 100 & 94 & 1271 \\
K.R. & 98 & 86 & 1960 \\
K.R. & 99 & 83 & 2756 \\
E.R. & 99 & 83 & \\
\hline
\end{tabular}

(1949) and of Soulié et al. (1954). From these data, it is concluded that there is no abnormality in the diffusion of oxygen across the alveolar-capillary membrane, even in the presence of severe pulmonary vascular disease.

(B) The greatest calculated pulmonary blood flows were not associated with arterial oxygen unsaturation, as shown in Fig. 4. This illustrates the tremendous reserve in the ability of the lung to oxygenate fully four to five times the amount of blood normally flowing through it.

(C) Minor degrees of arterial oxygen unsaturation were seen in a sizeable number of patients whose right ventricular outputs were of considerable magnitude (Fig. 4). This is interpreted as evidence that slight arterial unsaturation is attributable to mixing of both venous bloods in the common atrium, or perhaps to streaming of the blood from right to left sides of the common atrium (Selzer and Lewis, 1949; and Swan et al., 1954).

(D) It is also to be noted in Fig. 4, however, that the smaller the right ventricular output, the more likely the appearance of arterial oxygen unsaturation. In fact the patients with arterial oxygen saturations less than 90 per cent were the ones who had the smallest right ventricular outputs. This suggests that the more severe degrees of unsaturation are attributable to reversal of the shunt due to a low right ventricular output. The absence of cyanosis in earlier years suggests that these patients formerly had had greater right, ventricular outputs and that it was only when the right 


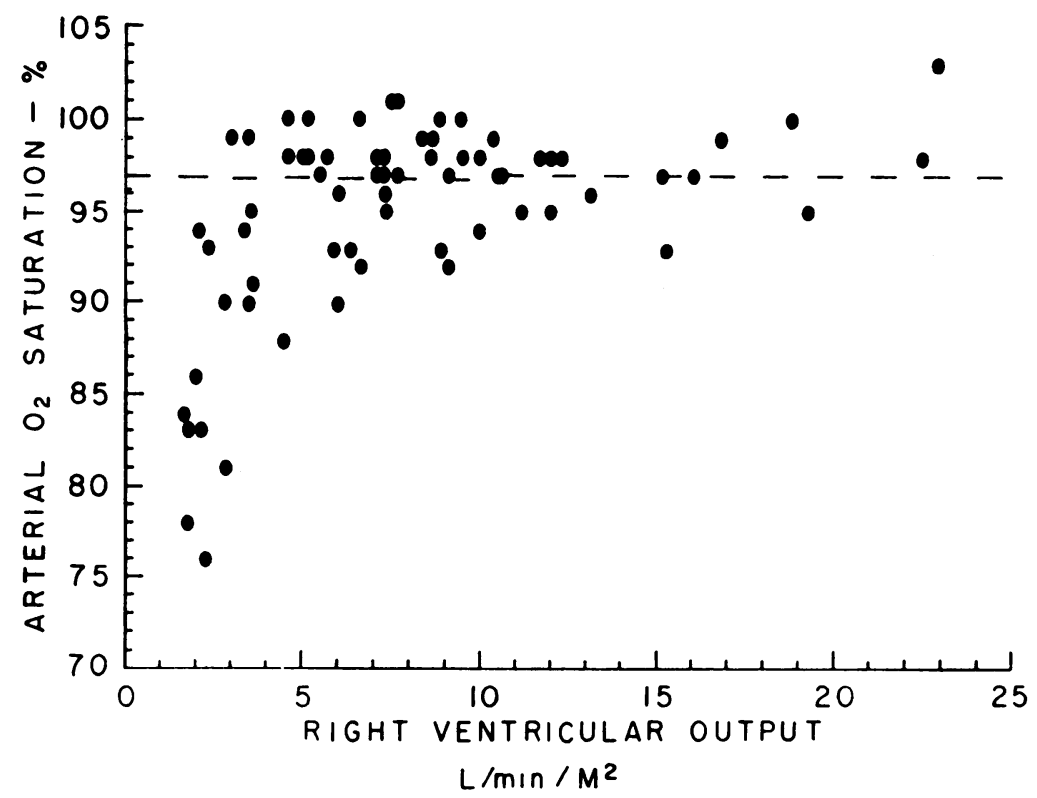

FIG. 4.-Relationship of arterial oxygen saturation to right ventricular output. The saturation is seen to be normal in most of those with huge pulmonary blood flows (or right ventricular outputs). Some patients have slight degrees of arterial oxygen unsaturation with high right ventricular outputs, but as the output of the right ventricle becomes less and less, approaching that of the left ventricle, the tendency to arterial oxygen unsaturation becomes more and more apparent. In this series, the most severe degrees of arterial oxygen unsaturation occurred in those with the smallest right ventricular outputs.

ventricular output approximated that of the left that a right-to-left shunt of sufficient magnitude to produce cyanosis occurred. In support of this, three patients who have been studied on two occasions 2 to 7 years apart have had a progressive fall of both arterial oxygen saturation and of right ventricular output (Table II). Such a reversal of shunt has usually been attributed to failure of the right ventricle leading to a higher pressure in the right than in the left atrium (Cournand et al., 1947; Little et al., 1949; Wood, 1950; Calazel et al., 1951; and Cosby et al., 1953). In 8 patients with arterial oxygen unsaturation, however, no measurable difference could be detected between the left and right atrial mean pressures in 4, and in 4 the mean pressures, as recorded, were $1 \mathrm{~mm} . \mathrm{Hg}$ higher in the left atrium than in the right. In four cases the tracings were sufficiently satisfactory to measure the end-diastolic pressures. In three, they were identical and in one it was, as recorded, $1 \mathrm{~mm} . \mathrm{Hg}$ higher in the left atrium than in the right.

TABLE II

Fall of Right Ventricular Output with Increasing Arterial $\mathrm{O}_{2}$ Unsaturation

\begin{tabular}{c|c|c|c}
\hline Patient & Year & $\begin{array}{c}\text { Right } \\
\text { ventricular } \\
\text { output } \\
\text { (litres/min./m. } .^{2}\end{array}$ & $\begin{array}{c}\text { Brachial arterial } \\
\text { oxygen } \\
\text { saturation } \\
\text { (percentage) }\end{array}$ \\
\hline E.R. & 1948 & $7 \cdot 1$ & 97 \\
F.S. & 1955 & $1 \cdot 8$ & 83 \\
A.B. & 1946 & $5 \cdot 0$ & 98 \\
& 1953 & $3 \cdot 6$ & 91 \\
\hline
\end{tabular}



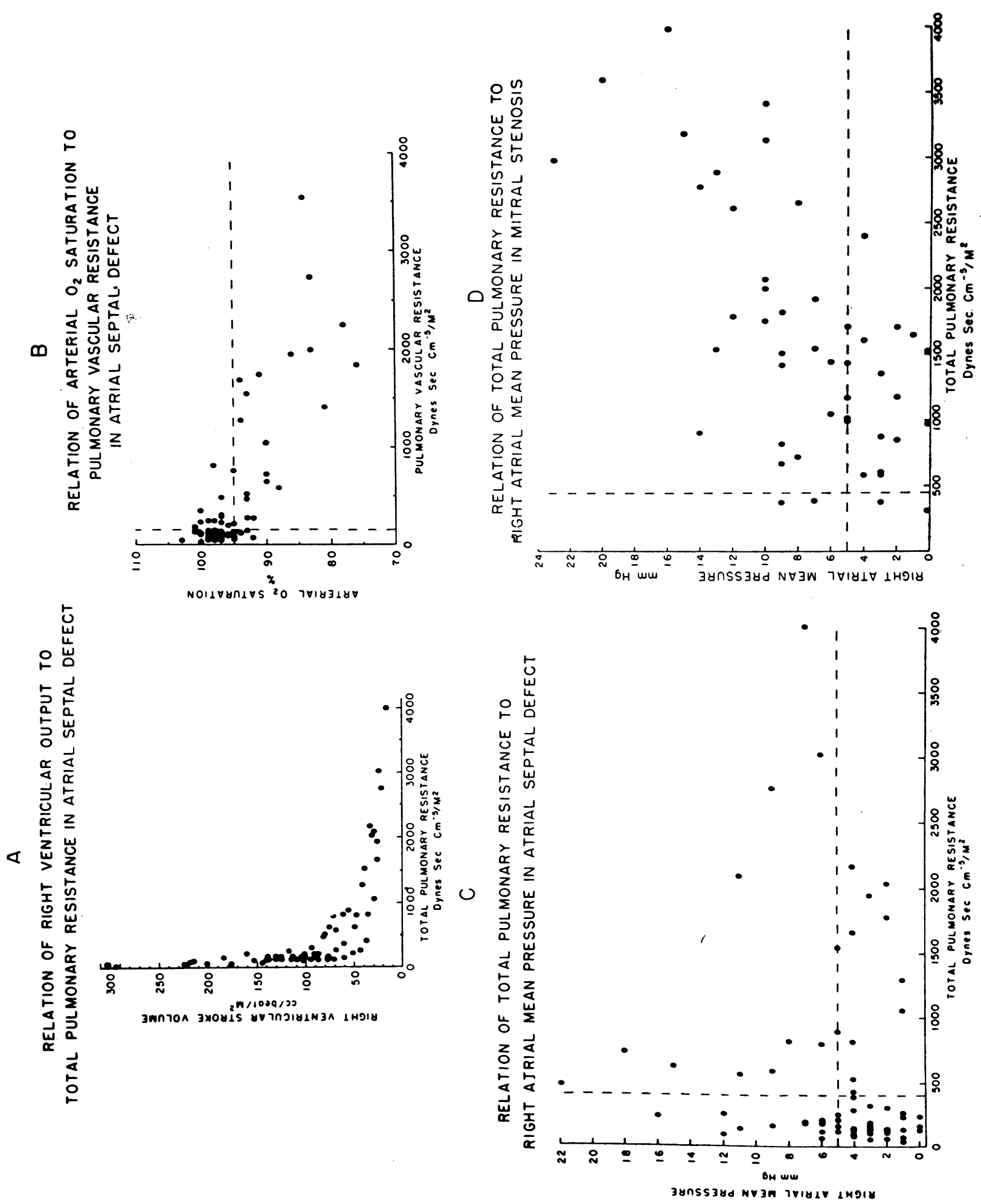

Fig. 5.-(A) As total pulmonary resistance rises, the right ventricular output falls. (B) As pulmonary vascular resistance rises, arterial oxygen unsaturation becomes more pronounced. (C) The highest diastolic pressures occurred in those patients with a minimal, if any, increase of total pulmonary resistance. In patients with the highest resistances, the right atrial pressure was only slightly raised. In these patients with an atrial septal defect, there is thus no relationship between total pulmonary resistance and the right atrial mean (or right ventricular diastolic) pressure. (D) In patients with mitral stenosis and an intact atrial septum, the direct relationship between right atrial pressure and total pulmonary resistance is apparent. 
In summary, minor degrees (and probably major degrees on occasion) of arterial oxygen unsaturation are due to mixing of systemic and pulmonary venous blood streams in the common atrium in these patients with atrial septal defect, while the more severe degrees manifested by clinical cyanosis are usually associated with a low right ventricular output with a reversal of shunt but $n o t$ associated with a higher pressure in the right atrium than in the left. It seems probable that as the outputs of the two ventricles approximate one another, mixing of the two venous blood streams is enhanced in the common atrium.

Although there are several possible causes of a progressive diminution of right ventricular output in these patients, one of the most important is the presence of an increase of pulmonary vascular resistance. This is not a unique relationship confined to patients with atrial septal defect. Exactly the same relation holds in pulmonary vascular disease from any cause (Dexter, 1951) including mitral stenosis (Gorlin et al., 1951). Fig. 5A shows that the higher the pulmonary resistance, the lower the right ventricular output. From the foregoing considerations, it then follows that the higher the pulmonary vascular resistance, the greater the tendency to arterial oxygen unsaturation (Fig. 5B). It has been demonstrated (Table I) that the unsaturation is not produced in the lung itself but only secondarily through the effect of an increased resistance in drastically reducing the right ventricular output; this facilitates mixing of systemic and pulmonary venous bloods in the common atrium and, in turn, leads to a right-to-left shunt. This leads, therefore, to a consideration of pulmonary vascular disease as it occurs in patients with atrial septal defect.

\section{Pulmonary Vascular Disease}

In 36 of the 67 studies, the pulmonary vascular resistance was considered to be normal, i.e. less than 160 dynes seconds $\mathrm{cm} .-5 / \mathrm{m} .{ }^{2}$ (see Fig. 2). In 31 , the value was above this figure. In 18 , it exceeded 500 , in 12 it exceeded 1000 , roughly 10 times or more the normal; the highest value was 3530 . These resistance figures give a rough measure of the difficulty blood encounters in passing through the pulmonary vasculature. The clinical importance of pulmonary vascular disease is that it is consistently associated with limitations heretofore absent and produces a progressively down-hill course culminating in death.

Vessels of the normal lung offer very little resistance to blood flow. The right ventricle can pump up to 10 litres/minute/sq.metre through the lung at relatively normal pressures (Dexter $\mathrm{et}$ al., 1950). The main circulatory effects of any type of obstruction in the central circulation such as the raised pulmonary vascular resistance in atrial septal defect are twofold. There is a reduction of blood flow and the pressure rises proximal to the obstruction. In the case of atrial septal defect, the pulmonary flow declines (Fig. 5A) and the pulmonary artery and right ventricular pressures rise (see Fig. 1).

A real increase of pulmonary vascular resistance has rarely been observed by us before the age of 20 (Fig. 6). Two patients, age 3 and 8, had a resistance of about twice normal: another had a similarly borderline elevation at the age of 12 , but on restudying him at 17 , an entirely normal value was found. The only patients of young age that we have seen with extremely high resistances have been those with an ostium primum type of defect or those with small atrial defects with what was interpreted as being primary pulmonary vascular disease. After the age of 20, an increased vascular resistance may or may not be present (Fig. 6); some of our patients in the fifth and sixth decades had normal resistances and some were raised. The lines with arrows in Fig. 6 represent our experience on restudying a small number of patients and demonstrate the increase of resistance that occurred over the span of a few years. This evidence seems to indicate that the increase of pulmonary vascular resistance in patients with atrial septal defect is an acquired abnormality affecting some but not all of the cases.

The nature of the increased pulmonary vascular resistance has been and is being the subject of intensive investigation on the part of many. Intimal proliferation of the pulmonary arterioles and small arteries occurs (Edwards, 1950; Evans, 1951; and personal observations) but, as in the case 
of systemic hypertension, it is not clear whether these lesions are the cause or the result of the pulmonary hypertension. Their distribution is patchy and not uniform. Vasoconstriction of the pulmonary vessels remains suspect but unproven. Although there is an increasing body of evidence suggesting that under certain circumstances the pulmonary vessels have powerful vasomotor activity, its nature, pharmacological response, and precise manner of behaviour are among the most important problems confronting the circulatory field at this moment. Wood (1952) has

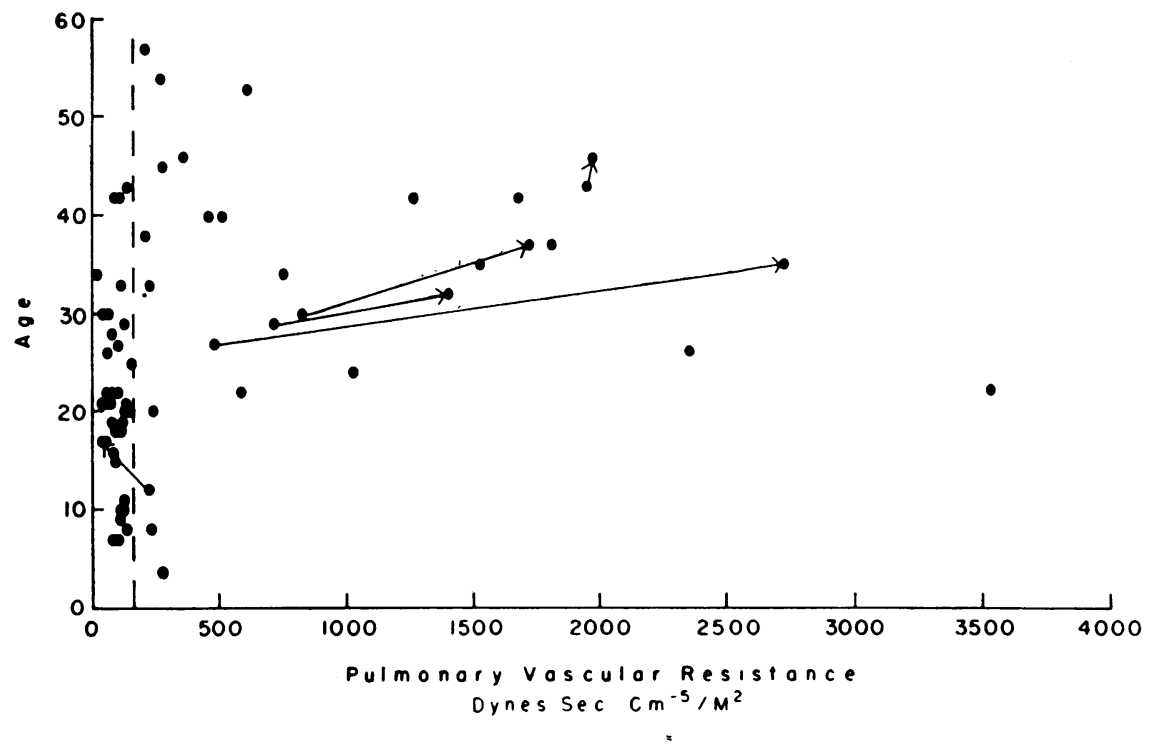

FIG. 6.-Relation of pulmonary vascular resistance to age. The vertical interrupted line represents the arbitrary upper limit of normal pulmonary vascular resistance. Note that in this series no real increase of resistance was found before the age of 20 , and that there was a progressive increase in those studied on subsequent occasions, as indicated by the arrows. Observe also that many patients even in the fourth and fifth decades had normal values for pulmonary vascular resistance.

observed that only 10 to 15 per cent of patients with lesions capable of provoking pulmonary vascular disease (atrial septal defect, ventricular septal defect, patent ductus arteriosus, mitral stenosis, etc.) actually develop severe grades of this vascular disorder. A corollary of this important observation is that in a similar proportion of patients with these same provocative stimuli, pulmonary vascular disease never develops.

Edwards (1950) has cited evidence to show that in Eisenmenger's syndrome, the high pulmonary vascular resistance is present at birth and represents a persistence of the fœtal type of vasculature which, during fœtal life, is a vasculature of high resistance. I am not aware that this has been demonstrated to occur in patients with atrial septal defect, but it has been suggested by Wood (1952), Evans, (1951), and others that the pulmonary vascular disease of atrial septal defect may have been on the basis of a congenital predisposition. Our own limited experience does not negate this thesis, but, as shown in Fig. 6, we have not found supporting evidence.

Thrombosis of the pulmonary vasculature has been demonstrated as a late event in many cases of atrial septal defect (Bedford et al., 1941; Evans, 1951; Massee, 1947; and personal observations) as well as of Eisenmenger's syndrome (Edwards, 1950) and occasionally patent ductus arteriosus associated with high pulmonary pressures (Chapman and Robbins, 1944; Douglas et al., 1947; Edwards et al., 1949). This, of course, produces a mechanical block to flow in all areas occupied by the thrombus. Sometimes the process is so extensive as to produce at necropsy a cast of the whole pulmonary arterial tree (Massee, 1947; and personal observations). How much benefit can be expected from prolonged anticoagulant therapy is problematical. It seems likely that extension 
of thrombosis can be prevented, but whether resolution or effective recanalization of the thrombus can be promoted seems doubtful. The unhappy circumstance is that the cross-sectional area of the pulmonary arterial tree must be reduced by two-thirds before a rise of pulmonary arterial pressure or a reduction of flow appear (Gibbon et al., 1932). In other words, no change in calculated resistance appears until the process is advanced. One cannot but wonder how many of our cases whose pulmonary vascular resistance was only slightly raised already had extensive thrombosis of the pulmonary vasculature.

The importance of this complication cannot be over-emphasized. From a surgical viewpoint, our limited experience and that of others (Swan, 1953; Bailey et al., 1954; and Kirklin et al., 1955) indicates that the risk of surgery rises pari passu with the severity of the pulmonary vascular disease, being prohibitive in the far-advanced cases. The reversibility of the pulmonary vascular disease associated with mitral stenosis by mitral valvotomy cannot be used as an argument that the pulmonary vascular disease of atrial septal defect will be similarly reversible following closure of the septal defect. The thrombotic nature of the pulmonary vascular disease of atrial septal defect is characteristically not seen in patients with mitral stenosis.

Thus, an important unsolved problem associated with atrial septal defect is the complication of the pulmonary vascular disease, its nature, pathogenesis, prevention, control and its reversibility.

\section{Ventricular FunCtion}

Ordinarily, the heart does not fail as a whole. The two sides fail in a separate fashion. The clinical manifestations of left ventricular failure are those of pulmonary congestion, and of right ventricular failure, systemic venous congestion. When a ventricle fails, there are two fundamental ways in which it can react-the first is a reduction of work load or output, the second is dilatation or stretching of the muscle fibre to increase the force of contraction (Patterson and Starling, 1914; and Lewis et al., 1953). If it dilates, it is an increase of diastolic pressure, ultimately produced by the other ventricle, that produces the dilatation. Thus, as ventricles fail, their work load or output may become reduced or their diastolic pressure may rise, or usually both occur.

As has been pointed out, in atrial septal defect the two ventricles can be considered to be in free communication during diastole. The problem arises as to which ventricle controls the diastolic pressure. Does right ventricular failure result in a rise of the diastolic pressure of the right ventricle and atrium as well as in the left ventricle and atrium, or is it with failure of the left ventricle that these pressures rise? There are three points of evidence indicating that when the right ventricle fails, its diastolic pressure remains unchanged and its output becomes reduced; but that when the left ventricle fails, its output, already low, is relatively unaffected (although there is a tendency for it to become slightly lower), the main effect being reflected in a rise of diastolic pressure. In so doing, the pressure in diastole rises in both atria, both ventricles, and both venous systems, with resultant congestion of pulmonary venous and systemic venous compartments. The evidence is as follows.

(a) The diastolic pressure in the two ventricles in relation to their output is shown in Fig. 7. As indicated by the crosses and the straight line, the left ventricular stroke output remains fairly constant over a wide range of diastolic pressure. At the higher diastolic pressure levels, the left ventricles are failing in the physiological sense that they are performing a subnormal amount of work at a filling pressure higher than is their wont and higher (by history) than they previously had had. Whether this is to be called ventricular failure or malfunction or by some other term is of little importance. We have chosen to call it failure until evidence is forthcoming that it is on some other basis. The important point is that in left ventricular failure, the output remains relatively stable only at the expense of a rise in diastolic filling pressure. On the other hand, as indicated by the dots in Fig. 7, there is no relationship whatever between the diastolic pressure in the right ventricle and its output (or, not shown here, pressure work). The right ventricle may eject large volumes of blood at low or high diastolic pressures, or small volumes at low or high diastolic pressures. In other words, these data show that the peripheral demands for blood continue to be met by a failing left ventricle by an elevation of its diastolic pressure, whereas the total lack of 


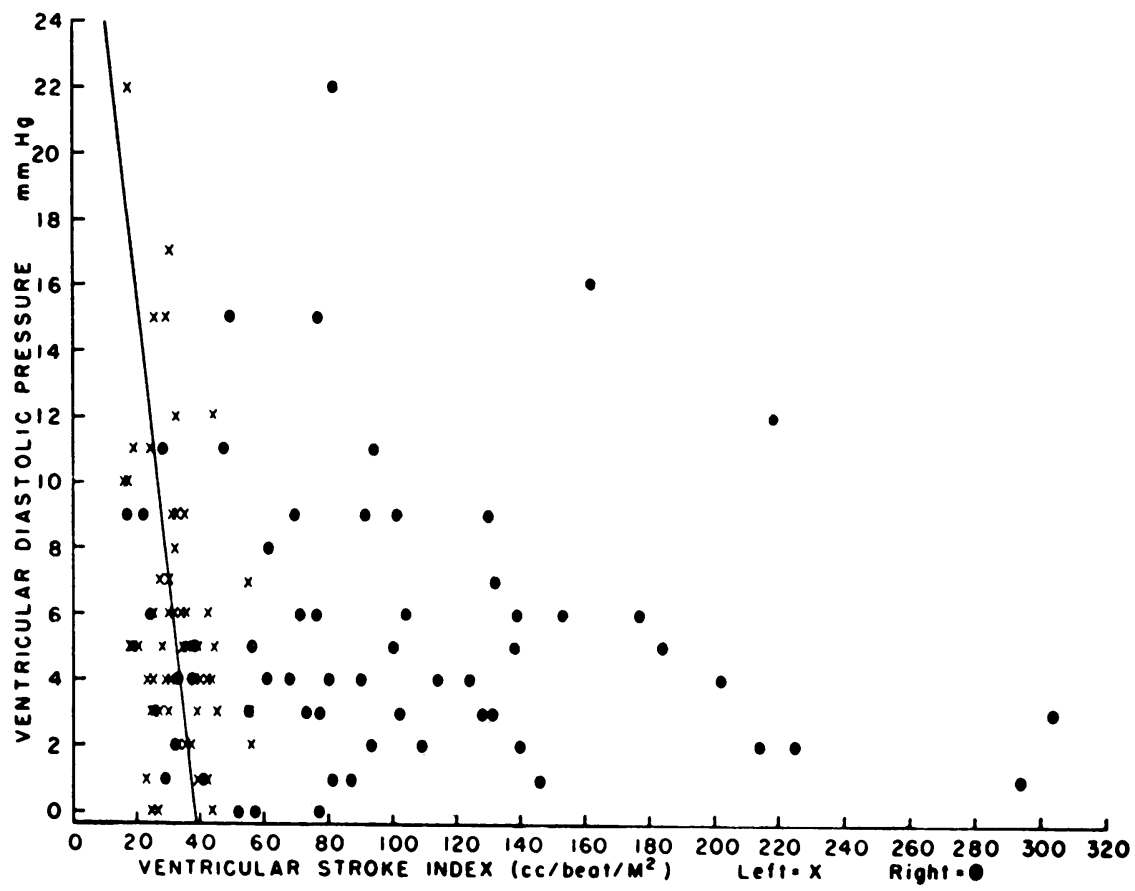

FIG. 7.-Relation of ventricular diastolic pressure to stroke volume of right and left ventricles. Left ventricular stroke volume $(X)$, already small, tends to become slightly smaller as left ventricular diastolic pressure rises. This shows that peripheral tissue needs for blood are fulfilled, but only through the mechanism of myocardial stretching (elevated diastolic pressure) which produces a more effective left ventricular systolic discharge (Patterson and Starling, 1914). There is no relationship whatsoever between right ventricular stroke volume $(\cdot)$ and its diastolic pressure.

relationship between right ventricular output and its diastolic pressure indicates that the right ventricle, having no control over its own filling pressure, behaves quite differently. These peculiarities will be discussed in more detail later.

(b) Pulmonary vascular disease is recognized to be a common cause of right ventricular failure (Dexter, 1951; and Lewis et al., 1952). It can be assumed to cause such failure in atrial septal defect. Fig. 5 shows the relation between an increase of pulmonary resistance on the one hand and right ventricular output and diastolic pressure on the other. There is a close inverse relation between pulmonary resistance and right ventricular output in these cases (Fig. 5A), but none whatsoever between the resistance and the right ventricular diastolic pressure (Fig. 5C). In other words, a complication known to cause failure of the right ventricle reduces the output of the right ventricle but appears to have no effect on its diastolic pressure. This is in striking contrast to mitral stenosis, with an intact septum, wherein the same relationship between total pulmonary resistance and reduced right ventricular stroke output holds (Gorlin et al., 1951), but the right ventricular diastolic pressure rises as the pulmonary resistance rises (Fig. 5D).

(c) The effect of acute digitalization on the hæmodynamics of eight patients with atrial septal defect has been studied. Administered to patients with normal hearts, digitalis causes a slight reduction of cardiac output and no significant change of ventricular pressure (Stewart et al., 1938). In the presence of heart failure, ventricular diastolic pressure falls and cardiac output increases (Stewart and Watson, 1938). Thus, digitalis is a useful agent for evaluating ventricular function, and we have applied it to the study of ventricular function in atrial septal defect. The left-hand columns of Fig. 8 show that the first four patients had no significant change of right ventricular output after acute digitalization. Three of these cases had no significant change of diastolic 
pressure, as indicated by the numbers above the columns and as nearly as could be determined were cases of uncomplicated atrial septal defect. The fourth (E.R.) had severe pulmonary vascular disease with a pulmonary vascular resistance of 2756 dynes seconds $\mathrm{cm} . .^{-5} / \mathrm{m}^{2}$ The next four patients had striking increases of right ventricular output without significant change of diastolic pressure in three and with a fall of diastolic pressure from 8 to $4 \mathrm{~mm}$. $\mathrm{Hg}$ in the first patient (D.K.). These findings indicate that if the right ventricle is competent, or if it is confronted with an extremely high pulmonary vascular resistance, acute digitalization has no effect on right ventricular output

\section{LEFT AND RIGHT VENTRICULAR STROKE VOLUMES BEFORE (घ) AND AFTER (অ) DIGOXIN 10 MG. I.V.}
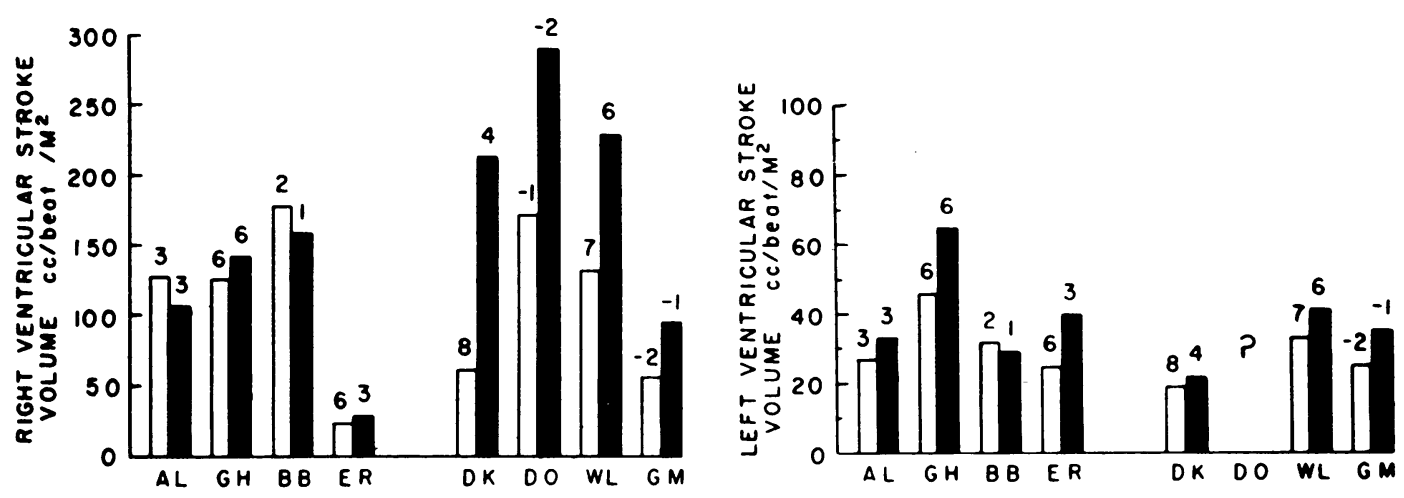

FIG. 8.-The effect of digitalis on right and left ventricular stroke volumes before (open columns) and 45 minutes after (black columns) the administration of $1.0 \mathrm{mg}$. digoxin intravenously. Numbers above the columns represent diastolic pressures. (See text for discussion.)

and diastolic pressures. If, on the other hand, the right ventricle has failed, there is an impressive increase in its output with no convincing change (in three out of four studies) of its diastolic pressure.

The effect of digitalis on left ventricular behaviour has not been well demonstrated so far because all cases with high diastolic pressures have had prior treatment with digitalis and thus could not be utilized for this special type of study. What results we have are shown in the seven columns on the right side of Fig. 8. There was a general tendency for left ventricular output to increase in six of the seven studies, but it should be noted that these increases were well within the error of the method in all but the second and perhaps the fourth case. In one patient (D.K.) there was a significant fall of diastolic pressure from 8 to $4 \mathrm{~mm}$. Hg. In one other (E.R.) there was a decrease from 6 to $3 \mathrm{~mm}$. $\mathrm{Hg}$.

These findings indicate that if the left ventricle is competent, digitalis has no significant effect upon either its output or its diastolic pressure. If incompetent, as in one case in borderline failure, indicated by a diastolic pressure of $8 \mathrm{~mm}$. $\mathrm{Hg}$, digitalis produced no significant increase of output but did result in a fall of diastolic pressure from 8 to $4 \mathrm{~mm}$. $\mathrm{Hg}$.

These observations raise an interesting point for speculation with respect to the advisability of digitalization of these patients. It would appear that digitalis increases the output of failing right ventricles, but in so doing it increases the left-to-right shunt and the pulmonary blood flow. Whether -or not this is a beneficial effect is not elucidated by our studies.

Fig. 9 is a schema to illustrate our concept of ventricular behaviour in the presence of large atrial septal defects, based on the data cited above. Uncomplicated atrial septal defects with competent left and right ventricles might be considered to have atrial and ventricular diastolic pressures of $2 \mathrm{~mm}$. Hg, a right ventricular output of 18 litres/minute, and a left ventricular output of 5 litres/ minute. With failure of the left ventricle, the diastolic pressure rises, and this rise is shared by 
both atria and both venous systems as well as the right ventricle during diastole. The left ventricular output is constant or at most declines only slightly, the right ventricular output theoretically increases slightly (from 18 to 20 litres/minute in this illustration) due to the increased stretch of muscle fibre from elevation of its diastolic pressure. With failure of the right ventricle, on the other hand, there is no change of its diastolic pressure or of that in the atria. Instead, its ability to empty itself during systole is imperfect and as it fails progressively, the residual volume increases and the stroke volume decreases.

The clinical implications of these observations are that manifestations of left ventricular failure

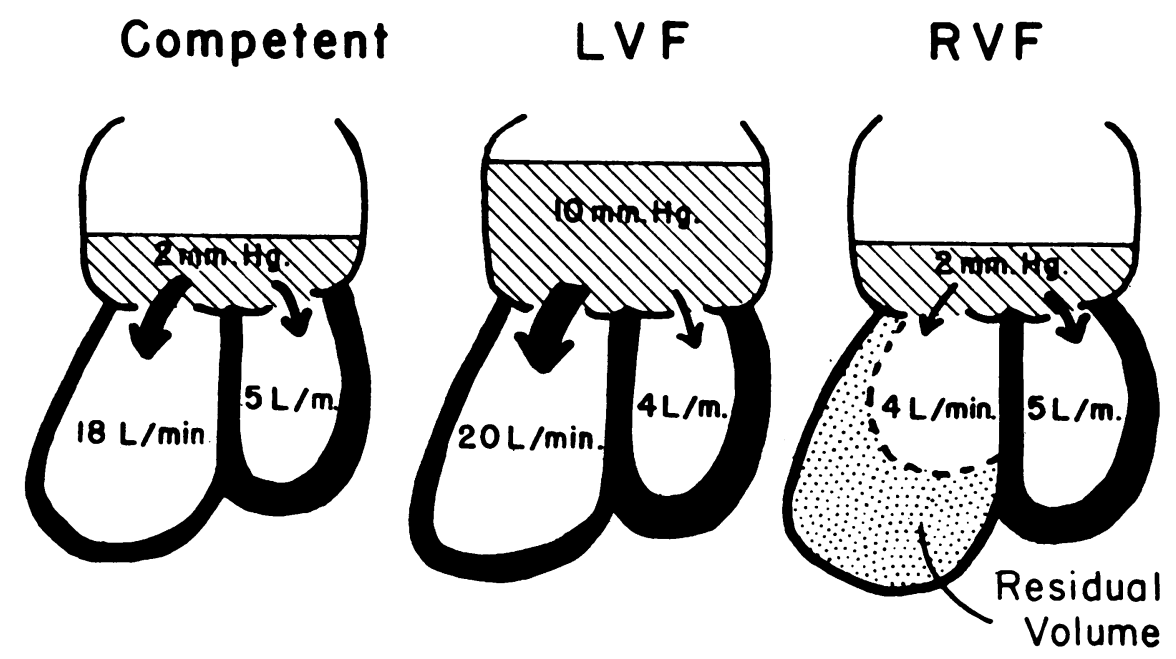

FIG. 9.-Schematic representation of ventricular function in the presence of an atrial septal defect. (See text for discussion.)

consist of congestion of both the pulmonary and systemic venous circuits. Right ventricular failure consists of a reduction of right ventricular output with an eventual reversal of shunt and cyanosis but no increase of its diastolic pressure and therefore no systemic venous congestion. Even tricuspid regurgitation, which must be a common complication of an atrial septal defect, has no effect on the right ventricular diastolic pressure or on the systemic venous pressure; its effect is merely to reduce the right ventricular output into the pulmonary artery.

\section{Right Ventricular Failure}

There are three obvious causes of right ventricular failure in these patients. One is the amount of work (pressure $\times$ flow) that the right ventricle performs. This calculation does not take into account the kinetic energy involved in imparting velocity to the huge flow of blood by the right ventricle. Ordinarily this is of little importance, but in these cases it must represent a tremendous expenditure of energy on the part of the right ventricle. In only six of our cases was the right ventricular pressure work load normal (see Fig. 1). In the remainder it was variably raised, the highest being over seven times the normal. In the uncomplicated cases, the increased work is largely flow work, which in general is well tolerated. Pressure work, however, is badly tolerated (Evans and Matsuoka, 1915). Thus, a second cause of right ventricular failure is the appearance of pulmonary vascular disease. In cases in whom this complication occurs, the work load on the right ventricle changes gradually from flow work to pressure work. It is in great part this effect which makes pulmonary vascular disease such a vicious complication. A third cause of right ventricular failure is tricuspid incompetence due to functional dilatation of the tricuspid ring and orifice. How often this occurs is difficult to state, as it may or may not be related to the presence or absence of pulmonary hypertension. Lack of descent of the $c$ wave in the right atrial pressure tracing is 
usually considered to be the earliest sign of its presence (Bloomfield et al., 1946). A high $v$ wave is occasionally found. None of our patients had high $v$ waves and only four had a lack of descent of the base. Only three had systolic pulsations of the liver. Thus, only a few patients had clinical or manometric evidence of tricuspid incompetence. It is assumed, however, that with a ventricle as dilated as that found characteristically in patients with atrial septal defect, tricuspid incompetence is a far commoner lesion than our findings would suggest. The inability to detect positive evidence of its presence may be attributable to the damping of regurgitant pressure waves by the combined volume of both atria and both venous systems into which the regurgitant blood is ejected. It is also apparent that the problem of differentiating tricuspid incompetence from mitral incompetence is difficult because the regurgitant streams through the orifice of both valves enter the same common atrium and both venous systems. In three of the six patients in whom clinical or hæmodynamic evidence of incompetence was considered to be present, operative or necropsy findings indicated the presence of mitral regurgitation. Thus, although tricuspid regurgitation is presumably present fairly commonly in patients with atrial septal defect, it has been identified only occasionally and even then has been difficult to differentiate from mitral incompetence.

How many of our patients had malfunctioning right ventricles is impossible to say. Short of the appearance of cyanosis, there is at present no means of recognizing a poorly functioning right ventricle except to study the effect of digitalis on the right ventricular output and shunt, and this is a cumbersome and laborious procedure.

\section{LEFT Ventricular Failure}

The question may well be asked why the left ventricle should fail in patients with atrial septal defect in which the left ventricle is by-passed by the shunt and does less work than it is normally expected to do. Fourteen of our cases had atrial pressures above $6 \mathrm{~mm}$. $\mathrm{Hg}$ and the causes of this elevation were as follows

Atrial pressure greater than $6 \mathrm{~mm}$. $\mathrm{Hg}$ (14 patients).

Demonstrable or possible rheumatic heart disease ( 9 patients).

Loud apical pansystolic murmurs and rheumatic deformity of mitral valve without stenosis at necropsy (4 patients).

Loud pansystolic apical murmur; X-ray calcification of mitral valve; no necropsy (1 patient).

Loud apical pansystolic murmurs, but no history of acute rheumatic fever and no necropsy ( 2 patients).

History of acute rheumatic fever, one with and one without a loud apical pansystolic murmur; no necropsy ( 2 patients).

Endocardial fibroelastosis of left ventricle with normal mitral valve at necropsy (1 patient). Hypertension (140/110) (1 patient).

Uncertain cause; no clinical clues; no necropsy (3 patients).

All five necropsied patients had demonstrable lesions imposing a strain on the left ventricle, another had calcification of the mitral valve radiologically, and another had systemic hypertension. Four other cases were suspected clinically of having similar lesions, and in only three was there no clue. In all cases, the suspected or demonstrated lesions affecting the left ventricle were relatively minor. It is doubtful if they would have caused significant disability in a normal heart, but they appear to be serious in these patients whose left ventricles are characteristically small and hypoplastic. In several of these cases, roentgen examination during life revealed left ventricles that appeared to be dilated. Post mortem, however, they had a small cavity and were hypoplastic. As far as I have been able to ascertain, their pressure-volume characteristics have never been studied and it is therefore difficult to decide whether or not during life they were actually larger because of their raised filling pressures and incomplete emptying, or were only apparently enlarged because of distortion of the cardiac silhouette by the tremendously enlarged right hearts.

Another explanation for the malfunction of the left ventricle has been the reverse of Bernheim's syndrome, i.e. the encroachment on the left ventricular cavity by the interventricular septum, causing an interference with filling. In two of our patients, Dr. Dwight E. Harken palpated the mitral valve and the cavity of the left ventricle during exploratory cardiotomy and described the 
obliteration of the left ventricular cavity by the septum. Just how much this would actually affect left ventricular function has not been investigated.

Another suggestion (Donovan, 1953; Wood, 1955; and Dornhorst, 1955) has been the limitation of left ventricular filling by the tension created by an over-stretched pericardium, resulting from the tremendous dilatation of the right heart. Against this explanation is that given time, as in these cases, the pericardium is capable of tremendous stretch, in contrast to its limited stretching capacity if the time course is short, as in cases of pericardial effusion or hæmopericardium. In five cases with raised atrial pressures the pericardium was not tense at the time of surgery. In fact, it was lax. The heart did not herniate through the incised pericardium as it frequently does in patients with constrictive pericarditis. Furthermore, there has been a poor correlation between heart size and atrial and ventricular diastolic pressures. Some of the biggest hearts in this series have had relatively normal diastolic pressures and some of those with a high atrial pressure have had a heart that was only slightly enlarged.

Our experience, therefore, indicates that relatively minor lesions imposing a burden on the left ventricle seem to be capable of causing the hypoplastic left ventricles of atrial septal defect to fail in the sense that there is a decreased work performance in the face of an abnormally high diastolic filling pressure. In each of five patients coming to necropsy with this complication, left ventricular lesions were demonstrable. A reverse of Bernheim's syndrome cannot be excluded, but seems unlikely as a basic factor; if it were, this complication would be expected to be more frequent and would be expected to bear a closer relation to heart size. Our observations give no support to a pericardial factor.

\section{LUTEMBACHER'S SYNDROME}

Mitral stenosis associated with atrial septal defect produces the same hæmodynamic change as does left ventricular failure except for the fact that the left ventricular diastolic pressure remains normal. The pressure in the left and right atria, right ventricle, and both venous systems rise. Tight mitral stenosis in association with atrial septal defect is rare (Nadas and Alimurung, 1952). We have seen two patients with large atrial septal defects and severe mitral stenosis, only one of whom was studied in detail (Rapaport et al., to be published). The differentiation of these cases from those with left ventricular failure has been difficult. In both there may be symptoms and signs of pulmonary and peripheral congestion, a loud apical first sound, an accentuated and split pulmonic second sound, an apical pansytolic murmur, and a classical mitral diastolic rumble with presystolic accentuation if the rhythm is regular, normal sinus rhythm or auricular fibrillation. An opening snap of the mitral valve was even heard in two patients who turned out not to have mitral stenosis (this latter observation was not checked by phonocardiography). Radiography, fluoroscopy, and electrocardiograms have yielded no differential features. The two conditions can be accurately differentiated only by cardiac catheterization. If the catheter can be passed through the atrial defect into the left atrium and thence through the mitral valve into the left ventricle, pressure records will reveal raised but equal diastolic pressures in the left ventricle and atrium in those cases with left ventricular failure, whereas in the presence of mitral stenosis, the left atrial diastolic pressure will be higher than the corresponding left ventricular pressure.

The importance of differentiating mitral stenosis from left ventricular failure in these cases is obvious. Relief of a severe mitral stenosis in two cases in our experience has resulted in dramatic clinical improvement. Complete closure of the atrial defect in seven patients who even after prolonged medical management in the hospital had markedly raised atrial pressure on the basis of left ventricular failure, has resulted in death in five. This is admittedly a small experience, but until now, at least, a discouraging one.

\section{SUMMARY}

The salient circulatory changes in 60 patients with atrial septal defect have been presented. The hæmodynamic observations have elucidated certain features of the pathological physiology of 
this condition. (1) A defect of sufficient size $(>2.0 \mathrm{sq} . \mathrm{cm}$. cross-sectional area) results in diminution or abolition of the normal atrial pressure difference between the two atria, producing a physiologically common atrium. (2) The left-to-right shunt is attributed to the different distensibility characteristics of the two ventricles such that at a common filling pressure the right ventricle achieves a far greater stroke volume than the left. (3) The magnitude of the left-to-right shunt, therefore, depends on the right ventricular output in relation to the left.

Information gained from this study has also clarified some of the physiological mechanisms underlying five complications that may or may not occur during the course of this disease: (1) cyanose tardive, (2) pulmonary vascular disease, (3) right ventricular failure, (4) left ventricular failure, and (5) mitral stenosis.

Cyanosis or arterial oxygen unsaturation is clearly due to a right-to-left shunt rather than to pulmonary factors. Minor degrees of unsaturation may be due either to random mixing of systemic and pulmonary venous blood in the common atrium or to a streaming effect. Severe degrees of unsaturation, on the other hand, are due to a decline in right ventricular output to a level approaching that of the left, thus facilitating interatrial mixing.

Pulmonary vascular disease is a vicious complication of atrial septal defect. In our experience its occurrence before adult life is exceptional. Pathologically it is characterized by obliterative intimal lesions and frequently by thrombosis of pulmonary arterial radicals, but its pathogenesis remains obscure. A rough estimate of its degree can be gleaned from the calculated pulmonary vascular resistance which in some cases may be enormous.

Right ventricular failure is most frequently a result of the increased pressure burden imposed by the development of pulmonary vascular disease, but also may be due to increased work or to tricuspid incompetence which clinically or physiologically may be impossible to differentiate from mitral incompetence. Right ventricular failure is characterized not by a raised diastolic pressure, but by a reduction in output leading eventually to a right-to-left shunt. The value of acute digitalization in assessing right ventricular function has been discussed.

Failure of the left ventricle in atrial septal defect has not as far as I know been described previously. We have observed this complication in 14 cases in this series. This is not surprising considering that the left ventricle is usually hypoplastic as a result of the by-pass just proximal to it. In our cases, left ventricular failure could usually be attributed to the existence of rather minor lesions that would ordinarily have little if any deleterious effect on left ventricular function. Physiologically, left ventricular failure is appreciated by a rise of diastolic pressure in the left ventricle as well as in both atria, both venous circuits, and right ventricle, and with only slight if any reduction in output.

Hæmodynamically significant mitral stenosis is a rare complication of atrial septal defect (Lutembacher's syndrome). Evidence indicates that it is extremely difficult, if not indeed impossible, to distinguish it from left ventricular failure unless the diastolic pressure gradient across the mitral valve is measured.

Over the past ten years, the part played by many colleagues too numerous to mention in the collection and interpretation of the material presented is acknowledged with gratitude and with a deep sense of indebtedness. Dr. Lawson McDonald contributed much to the recognition and understanding of the pathological physiology of mitral stenosis and left ventricular failure as it occurs in these patients. I am particularly under obligation to Dr. James W. Dow who, in 1949, studied the case material then available and reached many of the conclusions and interpretations presented here. Without his early unpublished contributions, this study would not have been possible.

\section{REFERENCES}

Bailey, C. P., Nichols, H. T., Bolton, H. E., Jamison, W. L., and Gomez-Almeida, M. (1954). Ann. Surg., 140, 805.

Barber, J. M., Magidson, O., and Wood, P. (1950) Brit. Heart J., 12, 277.

Bard, L., and Curtillet, J. (1889). Rev. de Méd., 9, 993.

Barger, J. D., Edwards, J. E., Parker, R. L., and Dry, T. J. (1948). Proc. Staff. Meet. Mayo Clin., $23,182$.

Bedford, E., Papp, C., and Parkinson, J. (1941). Brit. Heart J., 3, 37.

Bloomfield, R. A., Lauson, H. D., Cournand, A., Breed, E. S., and Richards, D. W., Jr. (1946). J. Clin. Invest., 25, 639. 
Brannon, E. S., Weens, H. S., and Warren, J. H. (1945). Amer. J. med. Sci., $210,480$.

Calazel, P., Gerard, R., Daley, R., Draper, A., Foster, J., and Bing, R. J. (1951). Bull. Johns Hopkins Hosp., 88, 20.

Chapman, C. B., and Robbins, S. L. (1944). Ann. intern. Med., 21, 312.

Cosby, R. S., Griffith, G. C., Zinn, W. J., Levinson, D. C., Dimitroff, S. P., Oblath, R. W., and Jacobson, G. (1953). Amer. J. Med., 14, 4.

Cournand, A., Motley, H. L., Himmelstein, A., Dresdale, D., and Baldwin, J. (1947). Amer. J. Physiol., $150,267$.

Dexter, L. (1951). Med. Rec. Ann., 45, 549.

-, Dow, J. W., Haynes, F. W., Whittenberger, J. L., Ferris, B. G., Goodale, W. T., and Hellems, H. K. (1950). J. Clin. Invest., 29, 602. - H47.

Donovan, T. (1953). Personal communication.

Dornhorst, A. C. (1955). Personal communication.

Douglas, J. M., Birchell, H. B., Edwards, J. E., Dry, T. J., and Parker, R. L. (1947). Proc. Staff. Meet. Mayo Clin., $22,413$.

Dow, J. W., and Dexter, L. (1950). J. Clin. Invest., 29, 809.

, and Maloney, J. V. (1951). Amer. J. Med., 10, 235.

Edwards, J. E. (1950). Proc. Inst. Med. Chicago, 18, 134.

, Douglas, J. M., Burchell, H. B., and Christensen, N. A. (1949). Amer. Heart J., 38, 205.

Evans, C. L., and Matsuoka, Y. (1915). J. Physiol., 49, 378.

Evans, W. (1951). Proc. Royal Soc. Med., 44, 600.

Gibbon, J. H., Hopkinson, M., and Churchill, E. D. (1932). J. Clin. Invest., 11, 543.

Gorlin, R., Haynes, F. W., Goodale, W. T., Sawyer, C. G., Dow, J. W., and Dexter, L. (1951). Amer. Heart J., 41, 30.

Handelsman, J. C., Bing, R. J., Campbell, J. A., and Griswold, H. E. (1948). Bull. Johns Hopkins Hosp., $82,615$.

Heim de Balzac, R., Métianu, C., Durand, M., and Dubost, Ch. (1954). Traité des Cardiopathies Congénitales. Paris.

Howarth, S., McMichael, J., and Sharpey-Schafer, E. P. (1947). Brit. Heart J., 9, 292.

Hull, E. (1949). Amer. Heart J., 38, 350.

Kirklin, J. W., Swan, H. J. C., Wood, E. H., Burchell, H. B., and Edwards, J. E. (1955). J. Thoracic Surg., $29,37$.

Lequime, J., Denolin, H., Goskel, F., Jonnart, L., and Wybauw, M. (1950). Acta Cardiol., 5, 302.

Lewis, B. M., Gorlin, R., Houssay, H. E. J., Haynes, F. W., and Dexter, L. (1952). Amer. Heart J., 43, 2.

, Houssay, H. E. J., Haynes, F. W., and Dexter, L. (1953). Circulation Research, 1, 312.

Limón Lasón, R., and Rubio Alvarez, V. (1949). Arch. Inst. Cardiol. México, 19, 545.

-, Esclavissat, M., Puech, P., de la Cruz, M. V., Rubio, V., Bouchard, F., and Soni, J. (1953). Arch. Inst. Cardiol. México, 23, 279.

Little, R. C., Opdyke, D. F., and Hawley, J. G. (1949). Amer. J. Physiol., 158, 241.

Martin, W. B., and Essex, H. E. (1951). Surgery, 30, 283.

Massee, J. C. (1947). Amer. J. med. Sci., 214, 248.

Nadas, A. J., and Alimurung, M. M. (1952). Amer. Heart J., 43, 691.

Patterson, S. W., and Starling, E. H. (1914). J. Physiol., 48, 357.

Puddu, V. (1952). Cardiol. Pratica, 3, 91.

Rapaport, E., Rabinowitz, M., Kuida, H., Haynes, F. W., and Dexter, L. (To be published.)

Selzer, A., and Lewis, A. E. (1949). Amer. J. med. Sci., 218, 516.

Soulié, P., Joly, F., Carlotti, J., and Sicot, J. R. (1950). Arch. Mal. Cour, 43, 97.

Swan, H. (1953). J. Amer. med. Ass., 151, 792.

Swan, H. J. C., Burchell, H. B., and Wood, E. H. (1954). Circulation, 10, 705.

Stewart, H. J., Crane, N. F., Deitrick, J. E., and Thompson, W. P. (1938). Arch. intern. Med., $62,547$.

Stewart, J. H., and Watson, R. F. (1938). Arch. intern. Med., 62, 569.

Wood, P. (1950). Brit. med. J., $2,693$.

- (1952). Brit. med. Bull., 8, 348.

- (1955). Personal communication. 